REVIEW ARTICLE

\title{
Cross-cultural studies on the prevalence of personality disorders
}

\author{
Barbara Gawda \\ Maria Curie-Skłodowska University (UMCS) in Lublin, Poland
}

This article reviews cross-cultural research on personality disorders. The concept of personality disorders is discussed in terms of whether they are universal phenomena or specific to Western society. Then, research on the prevalence of personality disorders in North America, South America, Europe, Asia, Africa, and Australia is reviewed. The overall rates of the prevalence of personality disorders range from $2.40 \%$ to $20.00 \%$. The data document that the prevalence of borderline and obsessive-compulsive personality disorders is the highest, especially in highincome countries. The cross-cultural differences in the prev- alence of the specified personality disorders are explained by its influencing factors such as race, ethnicity, social requirements, and the dimension of individualism-collectivism. The occurrence of personality disorders across cultures suggests some degree of psychological unity, and in turn, similarities in the neurobiological mechanisms of personality disorders.

\section{KEY WORDS}

personality disorders; prevalence; cross-cultural research; race; world wide

CORResPonding AUthor - Prof. Barbara Gawda, Maria Curie-Skłodowska University (UMCS) in Lublin, 5 Plac Litewski, 20-080 Lublin, Poland, e-mail: basia.gawda@poczta.umcs.lublin.pl

AUthors' CONTRIBUtion - A: Study design - B: Data collection - C: Statistical analysis · D: Data interpretation .

E: Manuscript preparation · F: Literature search · G: Funds collection

TO CITE THIS ARTICLE - Gawda, B. (2018). Cross-cultural studies on the prevalence of personality disorders. Current

Issues in Personality Psychology, 6(4), 318-329.

RECEIVED 17.09.2017 · REVIEWED 21.03.2018 · ACCEPTED 13.09.2018 · PUBLISHED 07.12.2018 


\section{BACKGROUND}

Personality disorders (PDs) are defined as relatively stable dispositions of maladaptive behavior. These patterns of one's inner experiences and behavior deviate from the norms and expectations of the culture the person lives in and impair self and interpersonal functioning (Butcher, Hooley, \& Mineka, 2016, p. 366; DSM-IV-TR, 2000, p. 275). PD diagnosis constitutes at least two of the following areas: cognitive, affective, interpersonal and impulse control (Cierpiałkowska \& Soroko, 2014). PDs were introduced into the DSM-III in the 1980 as a distinct clinical category. However, they had been present in the former versions of the DSM although not as a distinct notion. They have also been present in many psychological and medical concepts for a long time, such as in personality psychology, individual differences, and clinical psychology. In 2013 in the DSM-5, they were classified under Axis II and grouped into three clusters, A, B, and $C$. The International Classification of Diseases $10^{\text {th }}$ Edition (ICD-10) also includes PDs. Since the concept of PDs was first introduced in psychology and psychiatry, it has been suggested that PDs are related to dysfunctional emotional processing. People exhibiting PDs experience inadequate emotions, display problems with controlling them and have distorted emotional perception and interpretation. In turn, such impaired emotional processing leads to problems in perception and interpretation of the self and others (Cierpiałkowska \& Soroko, 2014; DSM-5, 2013, p. 311). Dysfunctional affective functioning is the main area which characterizes PDs. It manifests differently in different PD types. Researchers argued that dysfunctional affectivity in PDs is not fully characterized and understood (Trzebińska \& Gabińska, 2014) and is an important factor in the context of cross-cultural research on PDs. Experiencing emotions, emotional control, and regulation of emotions is dependent on the social and cultural milieu. Social rules of emotional expression determine how people experience and communicate emotions. These rules differ across countries, e.g. Latin Americans and Southern Europeans tend to express emotions more intensely while Asians (China) express themselves in a more reserved manner, with dependence and shyness being common qualities. Behavioral norms vary from one culture to another. This affects the formation and manifestation of personality as well as PD traits. In the literature, the relationship between PDs and culture is shown mainly through the comparison of prevalence rates between different countries, continents, and/or races. Researchers have argued that there are insufficient studies on the role of culture, ethnicity, and race in the diagnosis of PDs and that this aspect is overlooked (McGilloway, Hall, Lee, \& Bhui, 2010). In general, there are several focuses in a cross-cultural approach to PD: 1 . Scientists (psy- chologists, neurobiologists, cross-cultural researchers, and evolutionists) aim to understand ethnic determinants of PDs and they compare the prevalence rates between samples of a different ethnicity; 2. Research highlights the differentiation of personality disorders in people from different cultures and nations; 3 . The culture-independent approach states that PD is a universal concept of every culture, with gender, social environment, and culture being the main factors important for the diversity of PD traits.

\section{PERSONALITY DISORDER - A UNIVERSAL CONCEPT OR ONLY A WESTERN PHENOMENON?}

Although PDs are known in all cultures of the world, specified types are considered to be culturally biased (Bhugra \& Bhui, 2001). Cultural factors influence the development of PD symptoms and have a direct effect or influence on the diagnostic procedure. The potential impact of culture on PDs is considered further in the cross-cultural research which focuses on whether PDs are a Western or universal phenomenon. Some researchers argue that the diagnosis of $\mathrm{PDs}$ is a reflection of North American and Western European concepts of personality (Loranger, Janca, \& Sartorius, 1997). There are two opposing approaches to the culture-PD relation: cultural relativism and cultural universalism. Cultural relativism assumes that culture has an important impact on personality development - that mental health and mental illnesses are culturally dependent. Furthermore, psychiatrists and psychotherapists from this school (ethnically matched therapists) evaluate patients with respect to their ethnic and cultural background (Maramba \& Hall, 2002). The available scientific data document greater effectiveness with ethnically matched therapy (Zane et al., 2005). Cultural relativism emphasizes the development of ethnographic and descriptive analyses (McGilloway et al., 2010). In this approach personality and culture are seen as mutually influencing each other. Personality and behavioral patterns are primarily contextual and historically founded, and universal personality traits are questioned (Church, 2000). Identification of the socio-centric self-concept in Hindu Indians and more autonomous, universal egocentric self-concept in Americans are example findings with this approach (Shweder \& Bourne, 1984). Comparably, the independent self-concept was identified as predominant in Western cultures, while the dependent self-concept dominates in Africa, Asia, Latin America, and some Southern European countries, which view a person as more dependent on social relationships (Markus \& Kitayama, 1991).

In contrast to the culture-relativistic position of cultural psychiatry, the school of cultural universalism assumes that human personality is universal and 
independent of cultural influences (Poortinga \& Van Hemert, 2001). According to this approach, personality traits and PD traits are relatively stable individual differences in cognitive aspects, emotions, and behavior. Personality disorders may be described and characterized using the universal classifications under the DSM-IV or ICD-10. There are data indicating the culture-independent applicability of the construct of Axis II of the DSM-IV (Yang, McCrea, \& Costa, 2000). Studies on the prevalence of PDs report that they are widespread in both clinical and non-clinical world populations. Relatively consistent rates of PD prevalence in different countries are interpreted in line with cultural universalism so as to say that they are not specific to Western cultures. Comparably, the differences in prevalence rates in different countries are interpreted as not dependent on the cultural factors but on different sampling instruments and methods used in studies (Tyrer et al., 2010).

Furthermore, the relatively consistent rates of PDs in community populations suggest that PDs may be analyzed in terms of neurobiological/genetic determinants (Gawda, Bernacka, \& Gawda, 2016). The differentiation of PDs is not only due to social factors but also to biological and neuropsychological determinants. It has been pointed out that the PD etiology lies in the interaction between the core inherited biological vulnerability and environmental factors, and that personality traits including pathological personality traits arise from the functioning of the relevant brain systems (De Young, 2010). Personality disorder traits are associated with both structural and functional brain impairments (Gawda et al., 2016). Researchers indicate, for instance, that avoidant PD patterns such as hypersensitivity to negative evaluation, excessive fear of rejection, and avoidance in social relationships are associated with dysfunctional neurobiological mechanisms (Klumpp, Angstadt, \& Phan, 2012; Koenigsberg et al., 2014). Similarly, schizotypal PD, defined as a heterogeneous group with interpersonal, perceptual, and disorganized symptoms, is linked to brain structure and functional deficits (Cadenhead, Light, Geyer, McDowell, \& Braff, 2002; Hummelen, Pedersen, \& Karterud, 2012). Studies suggest that patients with schizotypal PD display dysfunctions in working memory (Rosell, Futterman, McMaster, \& Siever, 2014) and prospective memory (Vu et al., 2013; Wang et al., 2014) which are associated with functional and structural brain dysfunctions (Goldstein et al., 2011; Takahashi et al., 2011). Similarly, borderline PD (BPD), with a core pattern of emotional instability, is entrenched in a neural organization. Other features of the BPD - suicidality, outbursts of intense anger, stormy relationships, and identity disturbances - are all also associated with impaired neural mechanisms (Koenigsberg et al., 2009; Ruocco, Amirthavasagam, Choi-Kain, \& McMain, 2013). Neurobiological bases play a fundamental role in heightened attention, sensitivity to social-emotional cues in interpersonal scenarios, tendencies toward self-referential emotional processing, and dysregulated emotional processing in borderline patients (Donegan et al., 2003; Koenigsberg et al., 2009; Mitchell, Dickens, \& Picchioni, 2014). Not all PDs are described in terms of neuropsychological mechanisms, but the documented data support their neurobiological roots.

As they are characterized by relatively stable neurobiological mechanisms, PDs may also be analyzed in terms of a universal evolutionary perspective (Buss, 2009). In this approach, PDs are conceptualized as stable evolutionary strategies that respond to environmental stimuli (Buss, 2009). Personality traits reflect differences in effectiveness of adjustment to complex social interactions (Figueredo, Hammond, \& McKiernan, 2006). Personality disorders and the dysfunctional emotions incorporated in them play adaptive roles; personality disorder traits may be conceptualized as adaptive strategies to deal with painful situations (Molina et al., 2009).

\section{PREVALENCE OF PERSONALITY DISORDERS IN THE WORLD}

Studies on the prevalence of PDs are conducted in both clinical populations of the world as well as nonclinical.

Clinical populations. The PD rates in the clinical and psychiatric populations are high: from $30.00 \%$ to $70.00 \%$. It has been established that about $30.00 \%$ of psychiatric outpatients in the USA are diagnosed with at least one PD. The most frequent PD in psychiatric settings is borderline (Zimmerman, Rothschild, \& Chelminski, 2005). It is also highlighted that the high prevalence of PDs is frequently associated with other mental related disorders such as drug and alcohol abuse, and eating disorders (Chiesa, Fonagy, Holmes, Drahorad, \& Harrison-Hall, 2002; Pulay et al., 2009; Zimmerman et al., 2005). Afterward, the replication of the National Comorbidity Survey by Lenzenweger and associates (2007) on a representative clinical sample revealed that schizoid, schizotypal, and avoidant are the most prevalent PDs. Furthermore, cluster C PDs were found to commonly cooccur with other mental disorders, such as substance abuse, anxiety, and affective disorders (Hesse \& Moran, 2010; Mulder, 2002).

Non-clinical populations. A lower prevalence of PDs (4.00-10.00\%) in non-clinical community samples than in clinical samples is reported. Although PDs are widespread and have high and undifferentiated prevalence in the clinical settings, there is some differentiation in prevalence between community samples in different countries and cultures. It should be noted that there are limited data on cross-cultural 
differences in PDs. Furthermore, the interpretation of data on the prevalence of PDs in different countries is complicated by different disorder classifications, the variety of tools used in studies, and other methodological aspects (Tyrer et al., 2010). Coid and associates (2006) stated that there are only two studies on the prevalence of PDs that are based on representative populations and adjusted estimates provide reflection on real occurrence of PDs: the first by Torgersen, Kringlen, and Cramer in 2001, and the second by Samuels and associates (2002).

\section{NORTH AMERICA}

As for North America, most of the published data on the prevalence of PDs come from the USA. Data on the total rate and specified types of PDs are dependent on the type of the examined sample (clinical vs. non-clinical, student or community), assessment technique, and year of investigation. In 1989, Zimmerman and Coryell examined a sample of clinical patients' relatives and normal controls from Iowa with the DSM-III technique. They established that the overall rate of PDs was $14.30 \%$. Furthermore, the most frequent in this population were passiveaggressive and antisocial PDs (Zimmerman \& Coryell, 1989). Four years later, a study on the Iowa sample of relatives of obsessive-compulsive patients and normal controls was published (Black, Noyes, Pfohl, Goldstein, \& Blum, 1993). The small sample of 247 participants was tested with the DSM-III technique and a total rate of PD prevalence of $22.30 \%$ was found. Passive-aggressive and obsessive-compulsive were the most frequent PDs in this population (Black et al., 1993). In the same year, the results of the $\mathrm{Na}$ tional Comorbidity Survey were published, and they showed that the prevalence of antisocial PD in a large randomly selected non-clinical population of the USA was 5.60\% (Kessler et al., 1993). Moldin and associates (1994) established the prevalence of PDs at $7.30 \%$. The cited rate means that $7.30 \%$ of the population displayed at least one PD. They examined a small sample of normal controls from New York with the DSM-3-R technique, which revealed that the most frequent were antisocial and borderline PDs (Moldin, Rick, Erlenmayer-Kimling, \& Squires-Wheeler, 1994). One year later, based on the examination of a sample of normal controls from New York, the overall rate of PDs was established at $14.80 \%$, with avoidant and narcissistic as the most frequent PDs (Klein et al., 1995). Then, a sample of students from New York was examined and the overall rate of PDs was established as $11.00 \%$ (Lenzenweger, Loranger, Korfine, \& Neff, 1997). In a student population from New York, the most prevalent were histrionic and narcissistic PDs (Lenzenweger et al., 1997). Several years later, Samuels and associates (2002) examined a sample from Bal- timore where they reported the prevalence of PDs at $9.00 \%$ with the most frequent antisocial and avoidant PDs. They used the DSM-4 technique (First, Gibbon, Spitzer, Williams, \& Benjamin, 1997). Then, in 2004 more than 43000 individuals were examined with the DSM-IV technique in the National Epidemic Survey on Alcohol and Related Conditions of the USA. It was found that at least $14.80 \%$ of Americans had one PD. The findings were based on a random sample. The most prevalent PD in this study was the obsessivecompulsive PD (Grant et al., 2004). Comparably high PD prevalence was recorded in 2005: $15.70 \%$, as indicated in a study by Crawford and associates (2005). Similar data were published a few years later, where it was documented that about $11.39 \%$ (Lenzenweger, 2008), and/or $14.79 \%$ of American adults had at least one PD (Fowler, O’Donohue, \& Lilenfeld, 2007). However, the results of household surveys published by Huang and associates in 2006 revealed a lower prevalence of PDs in the USA, i.e. 7.60\%. It is important to note that Huang and associates (2009) used the 33-item screening questionnaire from the International Personality Disorder Examination in their survey, not the DSM-IV technique, which makes the results difficult to compare with previous studies.

In general, recent studies report that the prevalence of PDs in the US population ranges between $9.00 \%$ and $15.70 \%$ and some specific PDs, such as obsessive-compulsive, are most frequent. The high prevalence of this PD may be due to social requirements and the specifics of modern society. The expectations and requirements from an individual in modern societies have risen and may influence the identity and adjustment of a person (Paris, 2008). This affects mood and behavior, and results in emotional instability and potentially some traits of PDs. Modern societies, such as in North America, put a high demand on perfection and responsibility. People tend to fulfill their roles in social situations of high demands. This, in turn, may elicit inner conflicts, experience of being maladjusted and form a background for PD traits and behavior (Chang, 1965). This cultural pattern of the US society may cause an increase of obsessive-compulsive traits.

Data on the prevalence of PDs in a middle-low income Latin American country such as Mexico indicate lower PD rates. The Mexican National Comorbidity Survey was conducted in a large representative sample $(n=2362)$ of the Mexican urban adult population (Benjet, Borges, \& Medina-Mora, 2008). The International Personality Disorder Examination tool was used. The overall rate for any PD in Mexico is $6.10 \%$. The most prevalent are Cluster A disorders $(4.60 \%)$, then Cluster C $(2.40 \%)$ and Cluster B $(1.60 \%)$. The authors of the investigation concluded that almost half of those with a PD are likely to have an Axis I disorder. The rates of Cluster $\mathrm{C}$ disorders are much higher in the USA than Mexico, causing the 
stark difference between these countries in PD prevalence (Benjet et al., 2008). This result is in line with the idea of the impact that modern society has on PDs that was mentioned in the preceding section. However, the data on antisocial PD (1.80\% with predominance in males) show similar rates in the USA and Mexico (Benjet, Borges, Wagner, \& Medina-Mora, 2002), which suggests neurobiological etiology of this PD. This supports the reported significant brain dysfunctions in people with antisocial PD (i.e., Harenski, Harenski, Shane, \& Kiehl, 2010; Yang \& Raine, 2009).

There is a lack of data on PDs in Canada. The rate for antisocial PD is reported as $1.80 \%$ (Offord et al., 1996), which is similar to the USA and Mexico, and also suggests the neurobiological determinants of this disorder. In Canada, the prevalence of other PDs ranges from one to ten percent. It was also noted that PDs are more likely to contribute to the length of hospitalization (Stewart, Lips, Lakaski, \& Upshall, 2002).

\section{SOUTH AMERICA}

The data on PDs in South America are scarce. The overall rate in Colombia is $7.90 \%$, which is similar to the rate in Mexico (Huang et al., 2006). A study conducted in Brazil with the use of the Personality Disorders Dimensional Inventory showed that homeless people display antisocial, schizoid, and dependent PDs more often than others. However, in a non-clinical student group, borderline and obsessive-compulsive personality patterns of disorders were found to be frequent (Bartholomeu et al., 2015). The sample in this study was not, however, large and not randomized, which makes it difficult to compare these results with other studies. It has been indicated that people from Southern American countries may be misdiagnosed with two PDs: narcissistic and histrionic (Castaneda \& Franco, 1985). The typical patterns of histrionic PD are hyper-emotionality, seductiveness, somatization, and tendency to dramatize, which all reflect typical emotional expression and social norms in Latin American and Mediterranean countries. These patterns may be perceived as some symptoms of PDs (Calliess, Sieberer, Machleidt, \& Ziegenbein, 2008). Comparably, it has been thought that narcissistic PD, which is related to the aforementioned patterns, may be misdiagnosed in individuals from Southern Europe and/or Latin America (Loranger et al., 1994).

\section{EUROPE}

Data on PD prevalence in Europe are more similar to those of the USA than to South American countries. The rates reported in the literature are on occasion as low as the overall rate of $2.40 \%$ for Western Europe (Huang et al., 2006) but in general are rela- tively high. The prevalence of PDs in England, Wales and Scotland was examined using the SCID-II (Coid, Yang, Tyrer, Roberts, \& Ulrich, 2006). The researchers established that the overall unweighted rate was $10.70 \%$ and weighted $4.40 \%$. PDs from Cluster C are the most frequent, with obsessive-compulsive $\mathrm{PD}$ being the most prevalent (Coid et al., 2006; Moran, Rendu, Jenkins, Tylee, \& Mann, 2001). Several years later, a sample from England was examined and it was found that $13.70 \%$ of adults were screened positively for a PD (Moran, Rooney, Tyrer, \& Coid, 2016). General PD prevalence among men and women was similar. The rate for antisocial PD was higher in men $(4.90 \%)$ than in women (1.80\%). Positive screening for antisocial personality was also associated with age; in men aged $18-24$, the rate was $6.40 \%, 6.60 \%$ in men aged $25-34$, and $4.10 \%$ in older men. Then, $2.40 \%$ of a population of adults were screened positively for borderline PD; this disorder was present in both groups of men and women. In general, age was found to be also related to the PD rate: the older a person is, the lower the PD rate it has. Younger people are more likely to screen positively for borderline PD (Moran et al., 2016).

Data from another European country, Norway, were established in 2001 (Torgersen, Kringlen, \& Cramer, 2001). The researchers examined a community in Oslo and found that the PD rate was $13.40 \%$. The most prevalent was avoidant PD. In another Scandinavian country, Sweden, the most prevalent were narcissistic and obsessive-compulsive PDs (Bodlund, Ekselius, \& Lindstrom, 1993). A prevalence rate of $11.00 \%$ was established in a randomly selected Swedish community sample (Ekselius, Tillfors, Furmark, \& Fredrikson, 2001). Research confirmed that the most frequent PDs in the Swedish community were obsessive-compulsive (7.70\%), avoidant (6.60\%), and borderline (5.40\%) (Ekselius et al., 2001). A decade earlier, obsessive-compulsive PD was found as the most prevalent also in Germany (Maier, Lichtermann, Klingler, Heun, \& Hallmayer, 1992). This is consistent with the data on community samples in Scandinavian countries and the USA.

In regards to individuals from Mediterranean countries some findings documented that typical patterns of emotional expression such as hyper-emotionality, charm, and the tendency to dramatize may be misinterpreted as patterns of PDs. Spaniards, for example, tend to be unwilling to adjust to social standards and may be perceived as displaying histrionic or borderline PDs (Calliess et al., 2008). On the other hand, people from Eastern Europe might appear as more secretive or distrustful to an outsider, which can be wrongly attributed to PDs in Cluster C (Calliess et al., 2008).

Data on the prevalence of PDs in Poland are based on two publications. The first is a study conducted through the Internet on a nonclinical sample 
by Trzebińska and Gabińska (2014) that focused on the emotional characteristics of individuals with PDs and revealed data on their prevalence. They measured PDs using the Lifestyle 05/FS Questionnaire, a shortened, electronic version of the Lifestyle $05 / \mathrm{F}$ Questionnaire. The most frequent PDs were schizotypal $(8.60 \%)$, paranoid $(6.10 \%)$ and histrionic $(6.10 \%)$ (Trzebińska \& Gabińska, 2014). Then, a study on the prevalence of PD traits using the DSM-IV technique (the Structured Clinical Interview for the DSM-IV Axis II Disorders - SCID-II by First et al., 2010) was conducted by Gawda and Czubak (2017). A large community sample between 18 and 65 years old was randomly selected and interviewed. The results showed that the overall rate of PD traits was $8.90 \%$ and rates on sex differences were similar to other Western countries. The most prevalent in Poland are obsessive-compulsive (9.60\%), narcissistic $(7.00 \%)$, and borderline (7.00\%) PDs traits. These data are consistent with those in Sweden and the USA, with the exception of the narcissistic PD. This disorder was reported to be less frequent in other populations; however, the level of subclinical narcissism is reported as high in modern societies (Mac Donald, 2014; Twenge \& Campbell, 2009). Possibly, this is a PD which reflects some cultural aspect of the Polish community. This is in line with another study which showed that the average score for covert narcissism was higher in the Polish sample in comparison to the Dutch sample (Zondag, Van Halen, \& Wojtkowiak, 2009). Furthermore, these results showed greater comorbidity of PD traits than that which has been reported in the literature (Gawda \& Czubak, 2017).

Data on PDs in the Turkish population are sparse. There was a study conducted in Turkey with a community sample using the DSM-4 and ICD-10 Personality Questionnaire (DIP-Q) (Dereboy, Güzel, Dereboy, Okyay, \& Eskin, 2013). The results showed that $20.00 \%$ of the participants received a diagnosis of at least one PD. Among specified PDs, schizotypal and obsessive-compulsive were the most prevalent. The high prevalence of obsessive-compulsive PD is typical to all modern societies. However, a high rate for schizotypal personality is unique to the Turkish community population and probably reflects the specificity of the culture. The authors of this study stated that risk factors and personality dimensions were most strongly associated with the cluster B disorders (Dereboy et al., 2013).

\section{ASIA}

A lower prevalence of PDs is reported in community samples in Asian countries in comparison to the West; in the Republic of China, at least $4.10 \%$ of the population has one personality disorder, while in Lebanon it is $6.20 \%$ (Huang et al., 2006). Not only is the PD prevalence in China lower than in Western countries but also some PDs, such as avoidant, dependent, and borderline, are not specified in the Chinese Classification of Mental Disorders (Tang \& Huang, 1995). Interestingly, although the worldwide prevalence of borderline PD is the highest, it is not specified in the Chinese Classification. Borderline PD is more prevalent in the American than Spanish or Asian populations (Grant et al., 2008). Comparably, avoidant PD has not been reported in India (Loranger et al., 1997). Another difference is that antisocial PD is identified in all cultures at a similar rate while in Taiwan its prevalence is exceptionally low, at $0.20 \%$, while in the USA and other countries it is about $3.00 \%$ (Calliess et al., 2008). The findings in Taiwan were interpreted as reflecting cultural aspects associated with a common tendency to negate antisocial behavior and social rules of expression towards antisocial behavior. Asians and Filipinos express shame more frequently than Europeans and North Americans and have a different manner of expressing fear and passiveness. This might be attributed to some PD traits (Calliess et al., 2008). Some social attitudes may be related to philosophical aspects; Chinese interpersonal relationships are influenced by Confucian principles such as forgiveness, righteousness, and propriety (Kline, Horton, \& Zhang, 2008). On the other hand, modern societies, such as Japan, demand a high measure of responsibility and perfectionism from an individual, which may contribute to creating a background for PD behavior. Cultural components of Japanese society are perfectionism, carefulness, and orderliness (Chang, 1965). This, in turn, may be related to the high prevalence of obsessive-compulsive PD reported in Japan, the USA, and Europe (Calliess et al., 2008).

\section{AFRICA}

Prevalence of PDs in Africa is largely unknown. There are some findings such as the report on the overall PD rate in South Africa, which is $6.50 \%$, and the general prevalence of $2.70 \%$ in Nigeria (Huang et al., 2009). However, the tool used for the assessment was not the DSM-4 interview; it was the 33-item screening questionnaire from the International Personality Disorder Examination (IPDE). Thus, it is difficult to compare these results to the norms of the USA or Europe. Another study estimates the prevalence in South Africa as $6.80 \%$ (Suliman, Stein, Williams, \& Seedat, 2008). It is worth noting that no borderline PD was reported in Kenya, whereas, in general, the prevalence of borderline disorder increased in the last 30 years (Loranger et al., 1994). These findings are potentially related to some cultural aspects or they are incomplete. 


\section{AUSTRALIA}

Data showed that approximately $6.50 \%$ of the adult population of Australia has one or more PDs (Jackson \& Burgess, 2000). It was found that borderline personality is significantly associated with greater Axis I psychopathology among specific PDs (Jackson \& Burgess, 2004). A recent study using the Structured Clinical Interview for DSM-IV Axis II Personality Disorders showed that PDs are relatively common and occur at higher rates than previously estimated in the Australian population (Quirk et al., 2017). In women, the overall prevalence was established at $21.80 \%$. Cluster $\mathrm{C}$ is the most prevalent $(17.50 \%)$; obsessive-compulsive (10.30\%) and avoidant $(9.30 \%)$ were among the most prevalent PDs (Quirk et al., 2017).

\section{RACE AND ETHNICITY}

The aspect of a relationship between PDs, race, and ethnicity has been overlooked in the opinion of some researchers (McGilloway et al., 2010). They stress that there is still little known about the impact of culture, race, and ethnicity on the etiology and treatment of PDs (McGilloway et al., 2010). The degree to which the cultural context influences PDs is not fully described and only limited data are available from transcultural comparisons (Calliess et al., 2008). Earlier, Alarcon (1996) criticized the DSMIV for considering only a small part of experts' suggestions on transcultural aspects of PDs. Aspects such as self-image and adjustment associated with culture were not sufficiently touched upon in the DSM-IV. However, there are some data on relations between race, ethnicity, and prevalence of PDs. In regard to race and $\mathrm{PDs}$, no differences between black and white populations were found in the UK (Coid et al., 2006). Recent studies revealed that there was no significant association between PDs and ethnic groups (Moran et al., 2016). Furthermore, a meta-analysis showed a slightly but significantly lower prevalence of PDs amongst black as compared to white populations (McGilloway et al., 2010). Prevalence of PDs in Asian cultures is usually reported as lower than in white populations. Some disorders are not identified in Asian countries, e.g. avoidant personality in India or avoidant, dependent, and borderline PDs in China (Loranger et al., 1997). This is interpreted as being associated with social rules of emotional expression; e.g. Filipino more frequently and differently express shyness, anxiousness, and passiveness (Calliess et al., 2008). In regards to ethnicity, Latin Americans, Spaniards, and Southern European populations are thought to be more frequently misdiagnosed with histrionic or narcissistic PD traits, however, it does not mean that these disorders are highly prevalent in these populations (Loranger et al., 1994).

\section{INDIVIDUALISTIC VS. COLLECTIVIST CULTURES}

The dimensions mainly considered in cross-cultural studies on personality and PDs are individualism versus collectivism, dependence versus independence, and idiocentrism vs. allocentrism (Calliess et al., 2008). Individualist societies promote personal development and independence while collectivist cultures are more favorable to close relationships and intimacy (Dion \& Dion, 1993). Western societies and high income countries are typical individualist cultures. Thus, the high prevalence of obsessive-compulsive PD in modern societies may be related to individualism. On the other hand, a low prevalence of antisocial PD is observed in collectivistic cultures such as Taiwan. The occurrence of antisocial personality is principally independent of the socio-economic status; however, in collectivistic cultures, crime rates and this disorder rate are lower than in individualistic cultures (Cooke \& Michie, 1999; Harenski et al., 2010). It may reflect some general attitude toward antisocial behavior. Furthermore, dependence is not perceived as a symptom of a disorder in collectivistic cultures. Social distance respected by members of a society is typical for dependent/traditional cultures, and that is why this is not specified there as a psychopathological symptom (Loranger et al., 1997). Hence, dependent and avoidant PDs are not specified in the Chinese classification.

\section{CO-OCCURRENCE OF PERSONALITY DISORDERS}

In almost all studies presented here, the authors highlighted the co-occurrence of PDs, which has an impact on the presented results. The existing classification (with reference to the DSM-IV) generates comorbidity of several PDs across different clusters (Tyrer et al., 2010). In fact, the assessment of PDs using the DSM-IV (or previous techniques) indicates that a person displays different PD traits and different types of PDs including 'personality disorder not otherwise specified' (Bernstein, Iscan, \& Maser, 2007). It means that PD patterns overlap. This causes problems in the differentiation of specific PDs and consequently in treatment (Chiesa et al., 2002; Mulder, 2002). Potentially, this also causes overestimation/or incorrect estimation of rates of PDs worldwide, making it is difficult to compare results across different countries and continents (Paris, 2010). Another problem linked to the difficulty in comparison of the data presented here is due to the fact that they are based on different techniques as well as different sample sizes and types. This makes these comparisons not only difficult but also inadequate. In order 
to solve the problem of categorical PD diagnosis and comorbidity of several specified PDs, researchers suggested a dimensional approach to PDs (Moran et al., 2016). Therefore, future research that recognizes this approach will be comparable. The categorical diagnoses of PDs have been abandoned (Tyrer, Reed, \& Crawford, 2015). There has been proposed dimensional classification which extends from no personality dysfunction to severe PD, including intermediate levels as personality difficulty, mild and moderate PDs. There are empirical bases for this new severity-based classification (Moran et al., 2016). There are five trait domains which qualify the severity level: dissocial, anancastic, detached, negative affective, and disinhibited, which refers to normal personality variation. People diagnosed with PD have a disturbance in more than one domain (Mulder, Horwood, Tyrer, Carter, \& Joyce, 2016). The DSM-5 (2013) and the ICD-11 revision also take into consideration the evidence that PD is not stable over time (NewtonHowes, Clark, \& Chanen, 2015), which in turn results in two types of diagnoses: late-onset PD and PD in development (Tyrer et al., 2015).

\section{CONCLUSIONS}

PDs are widespread in all cultures of the world. The concept of PD is not specific to Western society. Prevalence rates in clinical populations are higher than in community samples; they range between $30.00 \%$ and $70.00 \%$, and are significantly comorbid with Axis I disorders. Prevalence rates in community populations are lower; they range from $4.50 \%$ to $21.50 \%$ and co-occur with disorders such as substance abuse, suicidal behavior, eating disorders, anxiety, and affective disorders. There is one PD that is highly prevalent world-wide whose world-wide rate has increased in the last 30 years; it is borderline PD. Importantly, research also indicates a high prevalence of obsessive-compulsive PD, especially in high-income modern societies. There are some differences between overall rates and rates of specified PDs associated with cultural aspects. For instance, in individualistic cultures, antisocial PD is identified more frequently than in collectivistic cultures. The avoidant and dependent PDs are not found in collectivist cultures. In some countries, such as Kenya and China, borderline PD is not identified. However, the degree to which race, ethnicity, and culture affect etiology, diagnosis, and treatment of PDs is not fully understood and covered in the literature. Future research is required to describe the relationship between culture, ethnicity, and personality pathology. The transcultural studies on PDs document its worldwide global occurrence and suggest a degree of psychological unity of PDs. This can be interpreted in terms of the evolutionary perspective and/or in terms of similarity between the neurobiological/ neurogenetic mechanisms of PDs among different nations (Figueredo et al., 2006; Gawda et al., 2016; Molina et al., 2009).

\section{REFERENCES}

Alarcon, R. (1996). Personality disorders and culture in DSM-4: a critique. Journal of Personality Disorder, 10, 260-270.

American Psychiatric Association (2000). Diagnostic and Statistical Manual of Mental Disorders ( $4^{\text {th }}$ ed.). Washington, DC: APA Publishing.

American Psychiatric Association (2013). Diagnostic and Statistical Manual of Mental Disorders ( $5^{\text {th }}$ ed.). Washington, DC: APA Publishing.

Bartholomeu, D., Montiel, J. M., Fiamenghi, G. A., Carvalho, L. F., Orsini, M. R., \& Ribeiro, C. R. (2015). Personality disorders in Brazilian homeless compared with non-psychiatric and psychiatric patients. Psychology, 6, 1022-1028.

Benjet, C., Borges, G., \& Medina-Mora, M. E. (2008). DSM-IV personality disorders in Mexico: results from a general population survey. Review of Brasilian Psychiatry, 30, 227-234.

Benjet, C., Borges, G., Wagner, F., \& Medina-Mora, M. E. (2002). Psychometric properties and construct validity of a Spanish language scale for screening antisocial personality. Social Behavior and Personality, 30, 223-234.

Bernstein, D. P., Iscan, C., \& Maser, J. (2007). Opinions of personality disorder experts regarding the DSM-IV personality d disorders classification. Journal of Personality Disorders, 21, 536-551.

Bhugra, D., \& Bhui, K. (2001). Cross-cultural psychiatry: A practical guide. London: Arnold.

Black, D. W., Noyes, R., Pfohl, B., Goldstein, R. B., \& Blum, N. (1993). Personality disorder in obsessive-compulsive volunteers, well comparison subjects, and their first degree relatives. American Journal of Psychiatry, 150, 1226-1232.

Bodlund, O., Ekselius, L., \& Lindström, E. (1993). Personality traits and disorders among psychiatric outpatients and normal subjects on the basis of the SCID screen questionnaire. Nordic Journal of Psychiatry, 47, 425-433.

Buss, D. M. (2009). How can evolutionary psychology successfully explain personality and individual differences. Perspectives on Psychological Science, 4, 359-366.

Butcher, J. N., Hooley, J. M., \& Mineka, S. (2016). Abnormal psychology $\left(16^{\text {th }}\right.$ ed.). Essex: Pearson Education.

Cadenhead, K. S., Light, G. A., Geyer, M. A., McDowell, J. E., \& Braff, D. L. (2002). Neurobiological measures of schizotypal personality disorder: defining an inhibitory endophenotype? American Journal of Psychiatry, 159, 869-871. 
Calliess, I. T., Sieberer, M., Machleidt, W., \& Ziegenbein, M. (2008). Personality disorders in a crosscultural perspective: Impact of culture and migration on diagnosis and etiological aspects. Current Psychiatry Reviews, 4, 39-47.

Castaneda, R., \& Franco, H. (1985). Sex and ethnic distribution of borderline personality disorder in an inpatient sample. American Journal of Psychiatry, 142, 1202-1203.

Chang, S. C. (1965). The cultural context of Japanese psychiatry and psychotherapy. American Journal of Psychotherapy, 19, 593-606.

Chiesa, M., Fonagy, P., Holmes, J., Drahorad, C., \& Harrison-Hall, A. (2002). Health service use costs by personality disorders following specialist and non-specialist treatment: a comparative study. Journal of Personality Disorders, 1692, 160-173.

Church, A. T. (2000). Culture and personality: toward an integrated cultural trait psychology. Journal of Personality, 68, 651-703.

Cierpiałkowska, L., \& Soroko, E. (2014). Zaburzenia osobowości. Problemy diagnozy klinicznej [Personality disorders. Problems of clinical diagnosis]. Poznań: UAM.

Coid, J., Yang, M., Tyrer, P., Roberts, A., \& Ulrich, S. (2006). Prevalence and correlates of personality disorder among adults aged 16 to 74 in Great Britain. British Journal of Psychiatry, 188, 423-431.

Cooke, D. J., \& Michie, C. (1999). Psychopathy across cultures: North America and Scotland compared. Journal of Abnormal Psychology, 108, 58-68.

Crawford, T. N., Cohen, P., Johnson, J. G., Kasen, S., First, M. B., Gordon, K., \& Brook, J. S. (2005). Selfreported personality disorder in the children in the community sample: convergent and prospective validity in late adolescence and adulthood. Journal of Personality Disorders, 19, 30-52.

De Young, C. G. (2010). Mapping personality traits onto brain systems: BIS, BAS, FFFS and beyond. European Journal of Personality, 24, 404-422.

Dereboy, C., Güzel, H. S., Dereboy, F., Okyay, P., \& Eskin, M. (2013). Personality disorders in a community sample in Turkey: Prevalence, associated risk factors, temperament and character dimensions. International Journal of Social Psychiatry, 60, 139-147.

Dion, K. K., \& Dion, K. L. (1993). Individualistic and collectivistic perspectives on gender and the cultural context of love and intimacy. Journal of Social Issues, 49, 53-69.

Donegan, N. H., Sanislow, C. A., Blumberg, H. P., Fulbright, R. K., Lacadie, C., Skudlarski, P., Gore, J. C., Olson, I. R., McGlashan, T. H., \& Wexler, B. E. (2003). Amygdala hyperactivity in borderline personality disorder: implications for emotional dysregulation. Biological Psychiatry, 54, 1284-1293.

Ekselius, L., Tillfors, M., Furmark, T., \& Fredrikson, M. (2001). Personality disorders in the general popu- lation: DSM-IV and ICD-10 defined prevalence as related to sociodemographic profile. Personality \& Individual Differences, 30, 311-320.

Figueredo, A. J., Hammond, K. R., \& McKiernan, E. C. (2006). A Brunswikian evolutionary developmental theory of preparedness and plasticity. Intelligence, 34, 211-227.

First, M. B., Gibbon, M., Spitzer, R. L., Williams, J. B. W., \& Benjamin, L. S. (1997). Structured Clinical Interview for DSM-IV Axis II Personality Disorders (SCID-II). Washington, DC: APA Publishing.

First, M. B., Gibbon, M., Spitzer, R. L., Williams, J. B. W., Benjamin, L. S., Zawadzki, B., \& Praglowska, E. (2010). Ustrukturalizowany wywiad kliniczny do badania zaburzeń osobowości z osi II DSM-IV [Structured Clinical Interview for DSM-IV Axis II Personality Disorders - SCID-II]. Warszawa: PTP. Fowler, K. A., O’Donohue, W. T., \& Lilenfeld, S. O. (2007). Personality disorders in perspectives. In W. T. O'Donohue, K. A. Fowler, \& S. O. Lilenfeld (Eds.), Personality Disorders. Toward the DSM-5 (pp. 1-20). Los Angeles: Sage.

Gawda, B., \& Czubak, K. (2017). Prevalence of personality disorders in a general population among men and women. Psychological Reports, 120, 503-519.

Gawda, B., Bernacka, R., \& Gawda, A. (2016). The neural mechanisms underlying personality disorders. NeuroQuantology, 14, 347-355.

Goldstein, K. E., Hazlett, E. A., Savage, K. R., Berlin, H. A., Hamilton, H. K., Zelmanova, Y., Look, A. E., Koenigsberg, H. W., Mitsis, E. M., Tang, C. Y., McNamara, M., Siever, L. J., Cohen, B. H., \& News, A. S. (2011). Dorso- and vetrolateral prefrontal volume and spatial working memory in schizotypal personality disorder. Behavioral Brain Research, 218, 335-340.

Grant, B. F, Chou, S. P., Goldstein, R. B., Huang, B., Stinson, F. S., Saha, T. D., Smith, S. M., Dawson, D. A., Pulay, A. J., Pickering, R. P., \& Ruan, W. J. (2008). Prevalence, correlates, disability, and comorbidity of DSM-IV borderline personality disorder: Results from the Wave 2 National Epidemiologic Survey on alcohol and related conditions. Journal of Clinical Psychiatry, 69, 533-545.

Grant, B. F., Hasin, D. S., Stinson, F. S., Dawson, D. A., Chou, S. P., Ruan, W. J., \& Pickering, R. P. (2004). Prevalence, correlates, and disability of personality disorders in the United States: results from the national epidemiologic survey on alcohol and related conditions. Journal of Clinical Psychiatry, 65, 948-958.

Harenski, C. L., Harenski, K. A., Shane, M. S., \& Kiehl, K. A. (2010). Aberrant neural processing of moral violations in criminal psychopaths. Journal of Abnormal Psychology, 119, 863-874.

Hesse, M., \& Moran, P. (2010). Screening for personality disorder with the Standardized Assessment of Personality: Abbreviated Scale (SAPAS): further 
evidence of concurrent validity. BMC Psychiatry, 10, 10. doi: 10.1186/1471-244X-10-10

Huang, B., Grant, B. F., Dawson, D. A., Stinson, F. S., Chou, S. P., Saha, T. D., Goldstein, R. B., Smith, S. M., Ruan, W. J., \& Pickering R. P. (2006). Race-ethnicity and the prevalence and co-occurrence of Diagnostic and Statistical Manual of Mental Disorders, Fourth Edition, alcohol and drug use disorders and Axis I and II disorders: United States, 2001 to 2002. Comprehensive Psychiatry, 47, 252-257.

Huang, Y., Kotov, R., de Girolamo, G., Preti, A., Angermeyer, M., Benjet, C., Demyttenaere, K., de Graaf, R., Gureje, O., Karam, A. N., Lee, S., Lépine, J. P., Matschinger, H., Posada-Villa, J., Suliman, S., Vilagut, G., \& Kessler, R. C. (2009). DSM-IV personality disorders in the WHO World Mental Health Surveys. The British Journal of Psychiatry, 195, 46-53.

Hummelen, B., Pedersen, G., \& Karterud, S. (2012). Some suggestions for the DSM-V schizotypal personality disorder construct. Comprehensive Psychiatry, 53, 341-349.

ICD-10 (1992). International Statistical Classification of Diseases and Related Health Problem. Geneva:WHO.

Jackson, H. J., \& Burgess, P. M. (2004). Personality disorders in the community: results from the Australian National Survey of Mental Health and Well-being, Part III. Relationships between specific type of personality disorder, Axis I mental disorders and physical conditions with disability and health consultations. Social Psychiatry and Psychiatric Epidemiology, 39, 765-767.

Jackson, H. J., \& Burgess, P. M. (2000). Personality disorders in the community: a report from the Australian National Survey of Mental Health and Wellbeing. Social Psychiatry and Psychiatric Epidemiology, 35, 531-538.

Kessler, R. C., McGonagle, K. A., Zhao, S., Nelson, C. B., Hughes, M., \& Eshleman, S. (1993). Lifetime and 12-month prevalence of DSM-II-R psychiatric disorders in the United States: Results from National Comorbidity survey. Archives of General Psychiatry, 51, 8-19.

Klein, D. N., Riso, L. P., Donaldson, S. K., Schwartz, J. E., Anderson, R. L, Ouimette, P. C., Lizardi, H., \& Aronson, T. A. (1995). Family study of early-onset dysthymia. Mood and personality disorders in relatives of outpatients with dysthymia and episodic major depression and normal controls. Archives of General Psychiatry, 52, 487-496.

Kline, S. L., Horton, B., \& Zhang, S. (2008). Communicating love: Comparisons between American and East Asian university student. International Journal of Intercultural Relations, 32, 200-214.

Klumpp, H., Angstadt, M., \& Phan, K. L. (2012). Insula reactivity and connectivity to anterior cingulate cortex when processing threat in general social anxiety disorder. Biological Psychology, 89, 273-276.
Koenigsberg, H. W., Denny, B. T., Fan, J., Liu, X., Guerreri, S., Mayson, S. J., Rimsky, L., New, A. S., Goodman, M., \& Siever, L. J. (2014). The neural correlates of anomalous habituation to negative emotional pictures in borderline and avoidant personality disorder patients. American Journal of Psychiatry, 171, 82-90.

Koenigsberg, H. W., Siever, L. J., Lee, H., Pizzarello, S., New, A. S., Goodman, M., Cheng, H., Flory, J., \& Prohovnik, I. (2009). Neural correlates of emotion processing in Borderline Personality Disorder. Psychiatry Research, 172, 192-199.

Lenzenweger, M. F. (2008). Epidemiology of personality disorders. Psychiatric Clinics of North America, 31, 395-403.

Lenzenweger, M. F., Lane, M. C., Loranger, A. W., \& Kessler, R. C. (2007). DSM-IV personality disorders in the National Comorbidity Survey Replication. Biological Psychiatry, 62, 553-564.

Lenzenweger, M. F., Loranger, A. W., Korfine, I., \& Neff, C. (1997). Detecting personality disorders in a nonclinical population. Application of a 2-stage procedure for case identification. Archives of General Psychiatry, 54, 345-351.

Loranger, A. W., Janca, A., \& Sartorius, N. (1997). Assessment and Diagnosis of Personality Disorders: The ICD-10 International Personality Disorder Examination (IPDE). Cambridge: Cambridge University Press.

Loranger, A. W., Sartorius, N., Andreoli, A., Berger, P., Buchheim, P., Channabasavanna, S. M., Regier, D. A. (1994). The International Personality Disorder Examination (IPDE). The WHO/ADAMHA International Pilot Study of Personality Disorders. Archives of General Psychiatry, 51, 215-224.

Mac Donald, P. (2014). Narcissism in the modern world. Psychodynamic Practice, 20, 144-153.

Maier, W., Lichtermann, D., Klingler, T., Heun, R., \& Hallmeyer, J. (1992). Prevalence of personality disorders (DSM-3-R) in the community. Journal of Personality Disorders, 6, 187-196.

Maramba, G. G., \& Hall, G. C. (2002). Meta-analyses of ethnic match as a predictor of dropout, utilization, and level of functioning. Cultural Diversity \& Ethnic Minority Psychology, 8, 290-297.

Markus, H. R., \& Kitayama, S. (1991). Culture and the self: Implications for cognition, emotion, and motivation. Psychological Review, 98, 224-253.

McGilloway, A., Hall, R., Lee, T., \& Bhui, K. (2010). A systematic review of personality disorder, race and ethnicity: prevalence, etiology and treatment. $B M C$ Psychiatry, 10, 33. doi: 10.1186/1471-244X-10-33

Mitchell, A. E., Dickens, G. L., \& Picchioni, M. M. (2014). Facial emotion processing in borderline personality disorder: a systematic review and metaanalysis. Neuropsychological Review, 24, 166-184.

Moldin, S. O., Rick, J. P., Erlenmayer-Kimling, L., \& Squires-Wheeler, E. (1994). Latent structure 
of DSM-3-R Axis II psychopathology in a normal sample. Journal of Abnormal Psychology, 2, 259-266.

Molina, J. D., López-Munoz, F., Stein, D. J., MartinVásquez, M. J., Alamo, C., Lerma-Carrillo, I., Andrade-Rosa, C., Sánchez-López, M. V., \& de la Calle-Real, M. (2009). Borderline personality disorder: A review and reformulation from evolutionary theory. Medical Hypotheses, 73, 382-386.

Moran, P., Rooney, K., Tyrer, P., \& Coid, J. (2016). Personality disorders. In S. McManus, P. Bebbington, R. Jenkins, \& T. Brugha (Eds.), Mental health and wellbeing in England: Adult Psychiatric Morbidity Survey 2014 (pp. 1-25). Leeds: NHS Digital.

Moran, P., Rendu, A., Jenkins, R., Tylee, A., \& Mann, A. (2001). The impact of personality disorder in UK primary care: a 1-year follow-up of attenders. Psychological Medicine, 31, 1447-1454.

Mulder, R. T. (2002). Personality pathology and treatment outcome in major depression: a review. American Journal of Psychiatry, 159, 359-371.

Mulder, R.T., Horwood, J., Tyrer, P., Carter, J., \& Joyce, P. R. (2016). Validating the proposed ICD-11 domains. Personality and Mental Health, 10, 84-95.

Newton-Howes, G., Clark, L. A., \& Chanen, A. (2015). Personality disorder across the life course. Lancet, 385, 727-734.

Offord, D. R., Boyle, M. H., Campbell, D., Goering, P., Lin, E., Wong, M., \& Racine, Y. A. (1996). One-year prevalence of psychiatric disorder in Ontarians 15 to 64 years of age. Canadian Journal of Psychiatry, 41, 559-563.

Paris, J. (2008). Recent advances in research on personality disorders. Current Psychiatry Reviews, 4, $10-13$.

Paris, J. (2010). Estimating the prevalence of personality disorders in the community. Journal of Personality Disorder, 24, 405-411.

Poortinga, Y. H., \& Van Hemert, D. A. (2001). Personality and culture: demarcating between the common and the unique. Journal of Personality, 69, 1033-1060.

Pulay, A. J., Stinson, F. S., Dawson, D. A., Goldstein, R. B., Chou, S. P., Huang, B., Saha, T. D., Smith, S. M., Pickering, R. P., Ruan, W. J., Hasin, D. S., \& Grant, B. F. (2009). Prevalence, correlates, disability, and comorbidity of DSM-4 schizotypal personality disorder: Results from the Wave II national epidemiologic survey on alcohol and related conditions. Primary Care Companion Journal of Clinical Psychiatry, 11, 53-67.

Quirk, S. E., Berk, M., Pasco, J. A., Brennan-Olsen, S. L., Chanen, A. M., Koivumaa-Honkanen, H., Burke, L. M., Jackson, H. J., Hulbert, C., Olsson, C. A., Moran, P., Stuart, A. L., \& Williams L. J. (2017). The prevalence, age distribution and comorbidity of personality disorders in Australian women. Australian \& New Zealand Journal of Psychiatry, 51, 141-150.
Rosell, D. R., Futterman, S. E., McMaster, A., \& Siever, L. J. (2014). Schizotypal personality disorder: a current review. Current Psychiatry Reports, 16, 452.

Ruocco, A. C., Amirthavasagam, S., Choi-Kain, L. W., \& McMain, S. F. (2013). Neural correlates of negative emotionality in borderline personality disorder: an activation-likelihood-estimation metaanalysis. Biological Psychiatry, 73, 153-160.

Samuels, J., Eaton, W.W., Bienvenu, O. J. III, Brown, C. H., Costa, P. T. Jr, \& Nestadt, G. (2002). Prevalence and correlates of personality disorders in a community sample. British Journal of Psychiatry, 180, 536-542.

Shweder, R. A., \& Bourne, E. J. (1984). Does the concept of the person vary cross-culturally? In R. A. Shweder \& R. A. LeVine (Eds.), Cultural theory: Essays on mind, self, and emotion (pp. 158-199). Cambridge: Cambridge University Press.

Stewart, P., Lips, T., Lakaski, C., \& Upshall, P. (2002). $A$ report on mental illnesses in Canada. Ottawa: Canadian Mental Health Association.

Suliman, S., Stein, D. J., Williams, D. R., \& Seedat, S. (2008). DSM-IV personality disorders and their axis I correlates in the South African population. Psychopathology, 41, 356-364.

Takahashi, T., Zhou, S. Y., Nakamura, K., Tanino, R., Furuichi, A., Kido, M., Kawasaki, Y., Noguchi, K., Seto, H., Kurachi, M., \& Suzuki, M. (2011). A follow-up MRI study of the fusiform gyrus and middle and inferior temporal gyri in schizophrenia spectrum. Progress in Neuro-Psychopharmacology \& Biological Psychiatry, 35, 1957-1964.

Tang, S. W., \& Huang, Y. (1995). Diagnosing personality disorders in China. International Medical Journal, 2, 291-297.

Torgersen, S., Kringlen, E., \& Cramer, V. (2001). The prevalence of personality disorders in a community sample. Archives of General Psychiatry, 58, 590-596.

Trzebińska, E., \& Gabińska, A. (2014). Features of emotional experiences in individuals with personality disorders. Polish Psychological Bulletin, 45, 147-155.

Twenge, J. M., \& Campbell, W. K. (2009). The narcissism epidemic: Living in the age of entitlement. New York: Free Press.

Tyrer, P., Mulder, R., Crawford, M., Newton-Howes, G., Simonsen, E., \& Ndetei, D. (2010). Personality disorder: a new global perspective. World Psychiatry, 9, 56-60.

Tyrer, P., Reed, G. M., \& Crawford, M. J. (2015). Classification, assessment, prevalence, and effect of personality disorder. Lancet, 385, 717-726.

Vu, M. A. T., Thermenos, H.W., Terry, D. P., Wolfe, D. J., Voglmaier, M. M., Niznikiewicz, M. A., McCarley, R. W., Seidman, L. J., \& Dickey, C. C. (2013). Working memory in schizotypal personality disorder: fMRI activation and deactivation differences. Schizophrenia Research, 151, 113-123.

Wang, Y., Yang, T., Su, L., Yan, C., Wang, Y., Huang, J., Fan, M., Yin, D., Jin, Z., Zeng, Y., Shum, D., Gur, R. C., 
\& Chan, R. C. K. (2014). Neural correlates of prospective memory in individuals with schizotypal personality features. Neuropsychology, 28, 373-381.

Yang, J., McCrea, R. R., \& Costa, P. T. (2000). The crosscultural generalizability of Axis-II construct: an evaluation of two personality disorder assessment instruments in the People's Republic of China. Journal of Personality Disorders, 14, 249-263.

Yang, Y., \& Raine, A. (2009). Prefrontal structural and functional brain imaging findings in antisocial, violent and psychopathic individuals. Psychiatry Research, 174, 81-88.

Zane, N., Sue, S., Chang, J., Huang, L., Huang, J., Lowe, S., Srinivasan, S., Chun, K., Kurasaki, K., \& Lee, E. (2005). Beyond ethnic match: effects of client-therapist cognitive match in problem perception, coping orientation, and therapy goals on treatment outcomes. Journal of Community Psychology, 33, 569-585.

Zimmerman, M., \& Coryell, W. (1989). DSM-III personality disorder diagnoses in a nonpatient sample. Demographic correlates and comorbidity. Archives of General Psychiatry, 46, 682-689.

Zimmerman, M., Rothschild, L., \& Chelminski, I. (2005). The prevalence of DSM-4 personality disorders in psychiatric outpatients. American Journal of Psychiatry, 162, 1911-1918.

Zondag, H. J., Van Halen, C., \& Wojtkowiak, J. (2009). Overt and covert narcissism in Poland and the Netherlands. Psychological Reports, 104, 833-843. 